\title{
Influence of Calcium Carbonate Nanoparticles on the Crystallization of Olypropylene
}

\author{
Daniel Eiras $^{\mathrm{a} *}$, Luiz Antonio Pessan ${ }^{\mathrm{b} *}$ \\ aPrograma de Pós-Graduação em Ciência e Engenharia de Materiais, \\ Departamento de Engenharia de Materiais, Universidade Federal de São Carlos - UFSCar \\ ${ }^{\mathrm{b}}$ Departamento de Engenharia de Materiais, Universidade Federal de São Carlos - UFSCar
}

Received: September 18, 2009; Revised: November 20, 2009

\begin{abstract}
The aim of this work was to study the influence of calcium carbonate nanoparticles in crystallization process of polypropylene. Four compositions of $\mathrm{PP} / \mathrm{CaCO}_{3}$ nanocomposites were prepared in a co-rotational twin screw extruder machine with calcium carbonate content of 3, 5, 7 and $10 \mathrm{wt}$. (\%). The tests included SEM analyzes for calcium carbonate, differential scanning calorimetry (DSC) and wide angle X-ray diffraction (WAXD) for the nanocomposites. The results showed an increase in PP crystallization temperature and crystallinity degree, and a reduction in spherullites size. The formation of PP $\beta$ phase was confirmed by DSC and WAXD results. Finally from DSC analyses under isothermal conditions it was confirmed that calcium carbonate nanoparticles have a nucleation effect in polypropylene crystallization process by reducing the half crystallization time and increasing the kinetic constant $(\mathrm{k})$.
\end{abstract}

Keywords: polypropylene, nanocomposites, calcium carbonate, crystallization

\section{Introduction}

Calcium carbonate nanoparticles have been widely used as fillers in polymeric materials with the main purpose of reducing $\operatorname{costs}^{1,2}$, however recently works showed that the incorporation of calcium carbonate nanoparticles can lead to higher impact resistance associated with higher elastic modulus ${ }^{3,5,6}$. The main mechanism of toughening semicrystalline polymers with the addition of inorganic fillers has been extensively discussed and involves stress concentration, debonding of the polymer/filler interface and the formation of shear bands. ${ }^{2}$ Besides this mechanism other effects, can lead to improved mechanical properties in semicrystalline polymers. The incorporation of inorganic fillers in semicrystalline polymers can change the crystallization process and the crystalline morphology and these changes can influence mechanical properties of semicrystalline polymers ${ }^{5,6}$. In previous work we showed that calcium carbonate nanoparticles leads to great increase in elastic modulus and reduction in brittle-to-ductile transition temperature, which means that the filler has a toughening effect in polypropylene. The results obtained in this work were correlated with the reinforcement effect of calcium carbonate in the case of elastic modulus and with the stress concentration factor of calcium carbonate in polypropylene in the case of toughening effect ${ }^{7}$.

Among all the effects that calcium carbonate nanoparticles can achieve in the crystallization of PP, some have been extensively reported in literature; formation of $\mathrm{PP} \beta$ phase as a consequence of the nucleation effect of the nanoparticles, higher crystallization temperature, lower half crystallization time and higher degree of crystallinity ${ }^{5,6}$.

In this context this work will present a series of analyses showing the effect of calcium carbonate nanoparticles in the crystallization and phase formation of an isotatic polypropylene and discuss which changes can affect the mechanical behavior of the polymer.

\section{Experimental}

\subsection{Materials}

Polypropylene homopolymer, grade H501-HC ( $\mathrm{MI}=3,5 \mathrm{~g} / 10$ minutes), was supplied by Braskem Petroquímica, Brazil. Calcium carbonate nanoparticles were supplied by YHnano, China. The mean diameter of the nanoparticles is between the range of 70-90 $\mathrm{nm}$.

\subsection{Preparation of the nanocomposites}

Before extrusion polypropylene and calcium carbonate nanoparticles were dry mixed in the desired compositions. Four compositions of nanocomposites with calcium carbonate content of 3, 5, 7 and 10 wt. (\%) were prepared in a co-rotational twin screw extruder machine Werner \& Pfleiderer ${ }^{\circledR}$ SZK 30 with screw diameter of $30 \mathrm{~mm}$ and $\mathrm{L} / \mathrm{D}=35$. The temperature profile was $170 / 190 / 190 / 190 / 190 / 195{ }^{\circ} \mathrm{C}$. Tensile test specimens were injected in an Arburg Allrounder $270 \mathrm{~V}$ injection molded machine according ASTM D638. The temperature profile was $215 / 220 / 235 / 245 / 250$ and the mold temperature was $55^{\circ} \mathrm{C}$.

\subsection{Characterization of calcium carbonate nanoparticles}

Calcium carbonate nanoparticles were characterized by SEM in a Phillips ${ }^{\circledast}$ XL30 microscope in order to determine the mean particle diameter.

\subsection{Characterization of the nanocomposites}

The nanocomposites were characterized by WAXD, DSC and optical microscopy. WAXD analyses were conducted in a Rigaku Geiger Flex equipment using $\mathrm{Cu} \mathrm{K} \alpha$ radiation, with $2 \theta$ varying from 5 to $90^{\circ}$. Thermal properties were characterized by DSC dur- 
ing heating and cooling and in the last case under isothermal and non-isothermal conditions. For non-isothermal analyses the sample was heated from 30 to $200{ }^{\circ} \mathrm{C}$ with a heating rate of $10{ }^{\circ} \mathrm{C} / \mathrm{min}$ and than cooled from 200 to $30^{\circ} \mathrm{C}$ with the same rate, from the results melting and crystallization temperature and the level of crystallinity (Equation 1) of PP and the nanocomposites were obtained. Isothermal analyses were conducted by heating the samples from 30 to $200{ }^{\circ} \mathrm{C}$ and cooling from $200{ }^{\circ} \mathrm{C}$ to the crystallization temperature of each sample. The results were fitted to Avrami equation (Equation 2) in order to determine the half crystallization time $\left(t_{1 / 2}\right)$, the kinetics constant $\mathrm{k}$ and the Avrami exponent (n). Finally polarized optical microscopy was conducted in a Leica DM RXP Wild MPS 32, the samples were heated and cooled in the same conditions described for DSC isothermal analyses.

$$
\text { Crystallinity }(\%)=\frac{\Delta H_{\text {melt.sample }}}{\Delta H_{\text {melt. } 100 \% \text { cristal. }} \times X_{P P}}
$$

$\left(1-X_{t}\right)=k t^{n}$

\section{Results}

\subsection{Morphology, chemical composition and surface treatment of the nanoparticles}

Figure 1 shows the morphology of the nanoparticles obtained from SEM analyzes. From the results it is possible to say that most of the nanoparticles have diameter in the range of 70-90 $\mathrm{nm}$. Moreover, the nanoparticles have a strong tendency to form agglomerates due to their high surface energy which is a result of the small particle size.

\subsection{Characterization of the crystalline structure of neat PP and $\mathrm{PP} / \mathrm{CaCO}_{3}$ nanocomposites}

Figure 2 shows the WAXD results for neat PP and the nanocomposites. From the results we see that neat PP presents peaks characteristics of $\alpha$ phase in $2 \theta$ values of $13,6,16,4 \mathrm{e} 18,2^{\circ}$ representing the crystallographic planes (110), (040) e (130), respectively ${ }^{10,11}$. For the nanocomposites the same planes appeared in $2 \theta$ values $14,2,16,9 \mathrm{e}$ $18,7^{\circ}$. The nanocomposites with calcium carbonate content of 3 and $7 \mathrm{wt}$. (\%) presented a peak in $2 \theta$ equal to $16,2^{\circ}$ which represents the (300) plane of PP $\beta$ phase $e^{4,5,10,11}$. $\beta$ phase is a metastable phase of PP with hexagonal geometry that appears under certain conditions of shear induced crystallization or in the presence of nucleating agentes ${ }^{8}$,

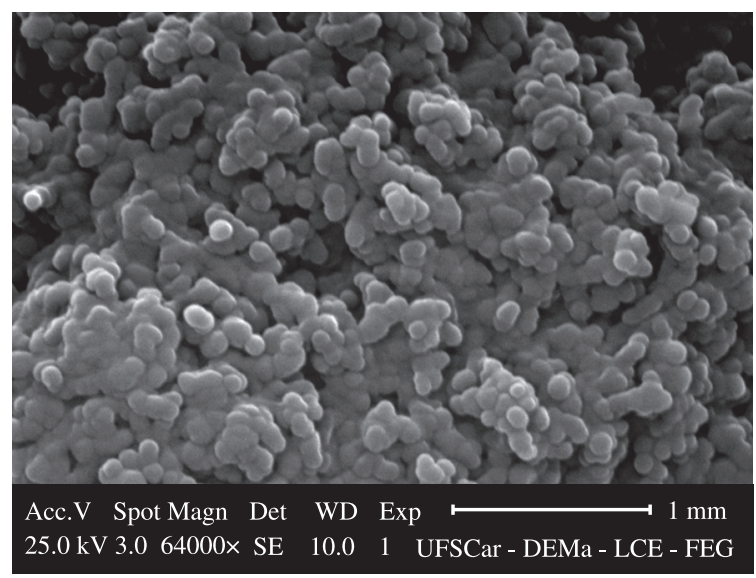

Figure 1. Morphology of calcium carbonate nanoparticles used in this work. like specific $\beta$ phase nucleating agents ${ }^{12}$ or inorganic fillers ${ }^{4,5,6,8}$. In this work the presence of $\beta$ phase can be attributed by the incorporation of calcium carbonate nanoparticles that lead heterogeneous nucleation in PP matrix during crystallization.

\subsection{Characterization of crystalline morphology of PP and the nanocomposites}

Figure 3 shows the images of the spherulitic structure of PP and the nanocomposites. From the images it is possible to say that the spherulites of PP were reduced with the incorporation of nanoparticles. Unfortunately it is impossible to determine the size of the spherulites in the nanocomposites. The reduction in spherulites size is due to the nucleation effect of calcium carbonate nanoparticles ${ }^{5}$. Smaller spherulites influence mechanical behavior of polymeric materials by increasing impact resistance and elongation at break, reducing elastic modulus and yield stress ${ }^{5}$.

\section{Thermal Properties}

\subsection{Melting behavior}

From the DSC analyses during heating it is possible to determine the melting point, level of crystallinity and the presence of different phases in semicrystalline polymers. As shown in Figure $4 a$ the melting temperature of PP was not influenced by the incorporation of calcium carbonate nanoparticles. In the other hand, from Figure $4 \mathrm{~b}$, it is possible to see that for the nanocomposites with calcium carbonate content of 5 and $7 \mathrm{wt}$. (\%) there is a second peak around $147^{\circ} \mathrm{C}$, representing $\beta$ phase of PP. As we already said in this work the formation $\beta$ phase in the presence of inorganic fillers is a result of the nucleation effect of the filler in the matrix crystallization process. Moreover $\beta$ phase is known to be tougher than $\alpha$ phase due to $\beta-\alpha$ polymorphic transition ${ }^{13,14,15}$ and some authors attributed to the presence of this metastable phase the higher toughness of $\mathrm{PP} / \mathrm{CaCO}_{3}$ nanocomposites ${ }^{4,5,8}$. At this point we will not consider this statement, that $\beta$ phase is responsible for higher toughness in our nanocomposites, because Lin Y. and coworkers reported that polypropylene/ calcium carbonate nanocomposites that were annealed for 2 hours in temperatures above the melting temperature of the $\beta$ phase presented higher impact resistance than the unannealed ones ${ }^{6}$. Although we can't say that the $\beta$ phase is responsible for any changes in mechanical properties of nanocomposites, its presence confirms that calcium

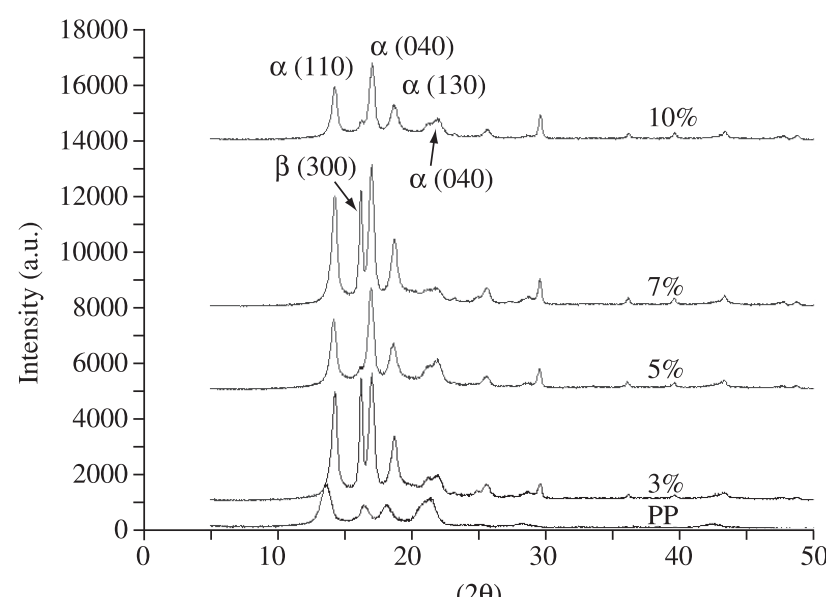

$(2 \theta)$

Figure 2. WAXD results for neat $\mathrm{PP}$ and $\mathrm{PP} / \mathrm{CaCO}_{3}$ nanocomposites. 

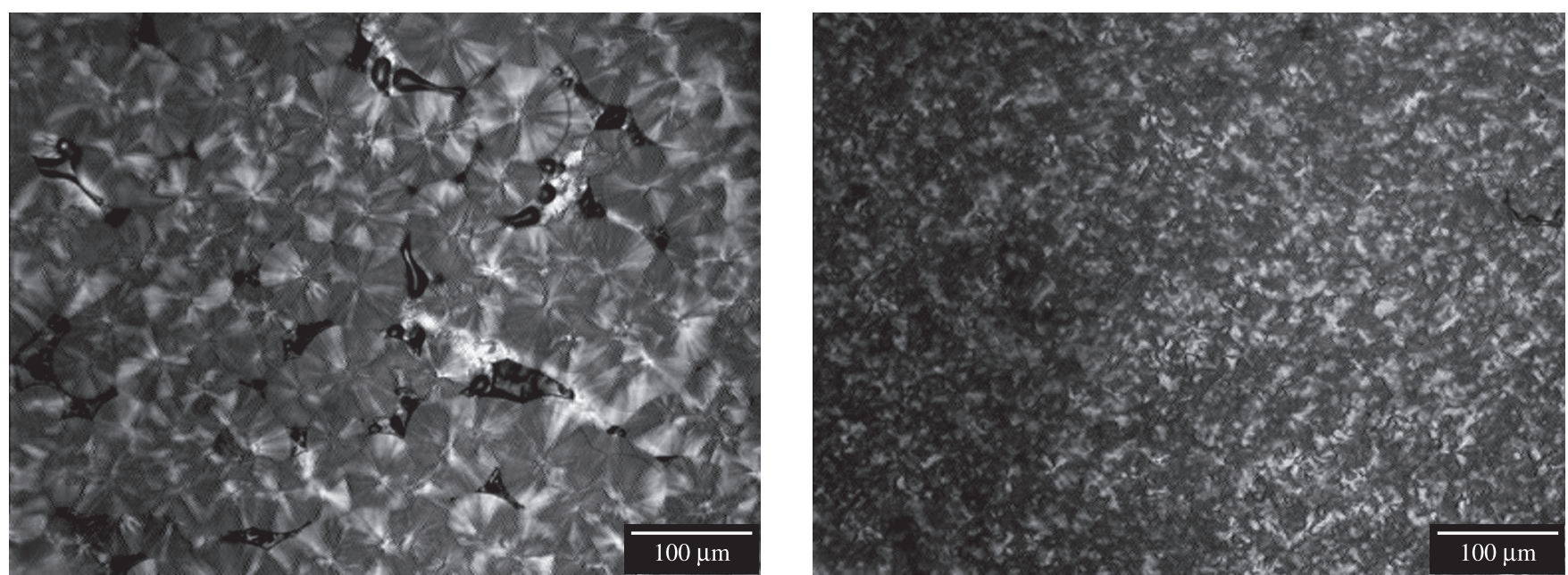

Figure 3. Crystalline morphology of $\mathrm{PP}(\mathrm{a})$ and $\mathrm{PP} / \mathrm{CaCO}_{3}$ nanocomposite with calcium carbonate content of 3 wt. (\%).

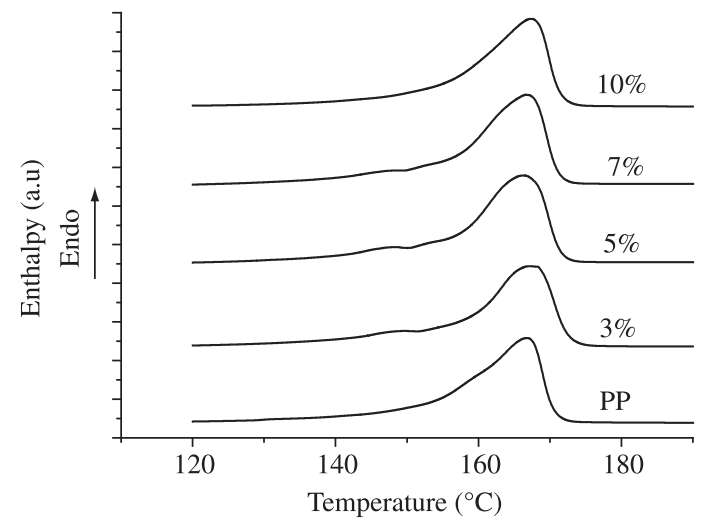

(a)

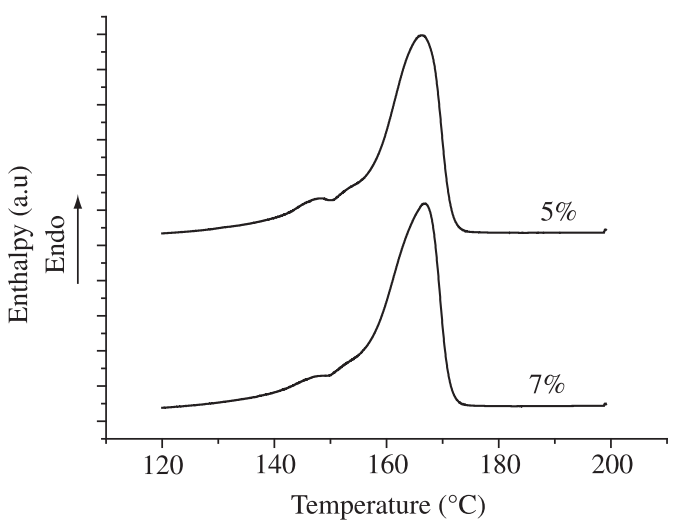

(b)

Figure 4. $\mathrm{DSC}$ curves under heating for $\mathrm{PP}$ and $\mathrm{PP} / \mathrm{CaCO}_{3}$ nanocomposites (a) and for $\mathrm{PP} / \mathrm{CaCO}_{3}$ nanocomposites with calcium carbonate content of 5 and 7 wt. $(\%)(b)$.

Table 1. Thermal properties of neat $\mathrm{PP}$ and $\mathrm{PP} / \mathrm{CaCO}_{3}$ nanocomposites.

\begin{tabular}{cccccc}
\hline Sample $\left(\mathrm{CaCO}_{3}\right.$ content $)$ & $\Delta \mathrm{H}_{\text {Met. }}\left({\left.\mathrm{J} . \mathrm{g}^{-1}\right)}^{-1}\right.$ & $\Delta \mathrm{H}_{\text {Crystall. }}\left(\mathrm{J} . \mathrm{g}^{-1}\right)$ & $\mathrm{T}_{\text {Melt. }}\left({ }^{\circ} \mathrm{C}\right)$ & $\left.\mathrm{T}_{\text {Crystall. }}{ }^{\circ} \mathrm{C}\right)$ & Crystallinity $(\%)$ \\
\hline $\mathrm{PP}(0)$ & 78,1 & 89,5 & 167 & 117 & 38 \\
$3 \%$ & 81 & 92,5 & 167 & 126 & 40 \\
$5 \%$ & 88 & 101,2 & 166 & 124 & 45 \\
$7 \%$ & 88,3 & 97,7 & 167 & 124 & 46 \\
$10 \%$ & 82,4 & 94,4 & 167 & 124 & 44 \\
\hline
\end{tabular}

$\Delta \mathrm{H}_{\text {Melting }}$ for neat PP $100 \%$ crystallized $208{\mathrm{~J} . \mathrm{g}^{-1} .{ }^{12}}^{12}$

carbonate nanoparticles affect the phase formation in polypropylene crystallization and suggests that it affects the crystallization kinetics too. Table 1 summarizes the results obtained in all DSC analyses, and shows that the level of crystallinity of PP was enhanced with the incorporation of calcium carbonate nanoparticles.

\subsection{Crystallization under non-isothermal conditions}

From Table 1 it is possible to see an increase in crystallization temperature of PP with the addition of nanoparticles. The incorporation of inorganic filers in semicrystalline polymers tend to increase the rate of crystallization, which results in higher crystallinity, higher crystallization temperature and smaller spherullites ${ }^{16}$. So the results showed until this point give strong evidences of the nucleation effect of calcium carbonate nanoparticles in PP matrix.

\subsection{Crystallization under isothermal conditions}

As we have many evidences that the incorporation of calcium carbonate nanoparticles influences the crystallization kinetics of polypropylene DSC analyses under isothermal crystallization were conducted in order to confirm this effect. Figure 5a presents the relation between the crystallized fraction and the time fitted to the Avrami equation. The Avrami index (n) and the kinetics constant (k) 


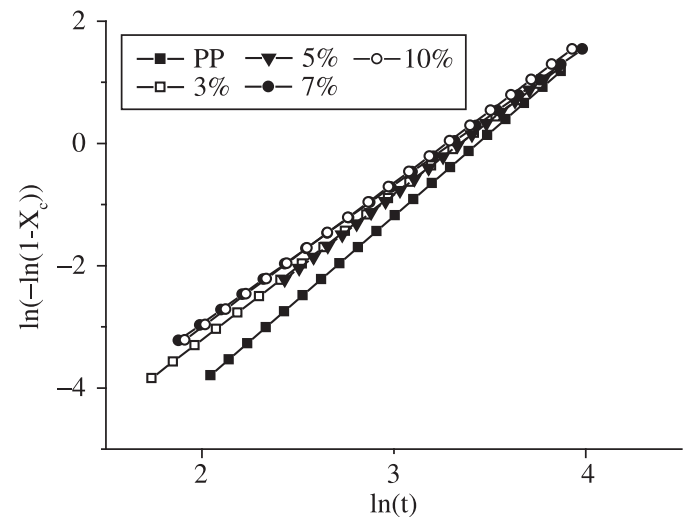

(a)

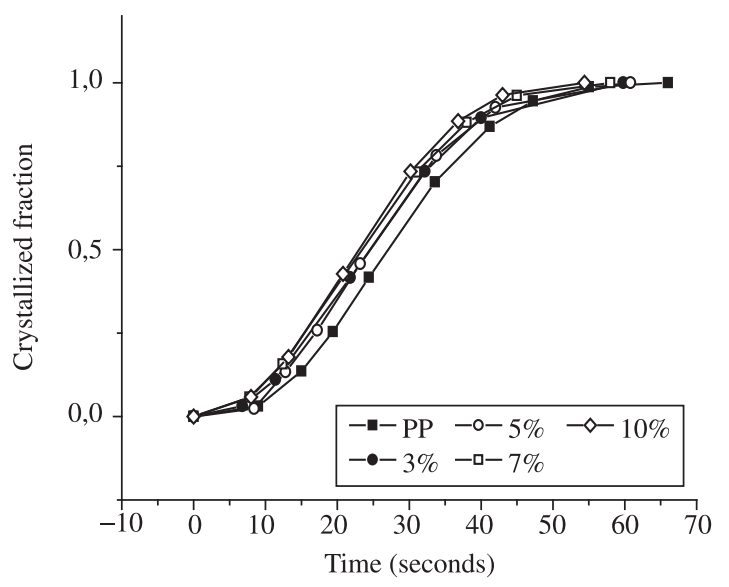

(b)

Figure 5. Experimental data fitted to the Avrami equation (a) and crystallized fraction vs. time (b).

were determined from the curves and are presented in Table 2. The values of $\mathrm{n}$ lied between 2 and 3, which is in accordance with data in literature for polypropylene/calcium carbonate nanocomposites ${ }^{8,19}$ and were not affected by the presence of nanoparticles, and the values of $\mathrm{k}$ increased with the incorporation of nanoparticles. Avrami index values between 2 and 3 indicate that the crystal geometry growth is bidimensional ${ }^{18}$ which do not correspond to the spherulitic structure obtained in polarized optical microscopy. This can be explained by the fact that Avrami model does not take in account some the statements that influences the heterogeneous crystallization, like the need of the polymer molecules to occlude, deform or reject the nanoparticles ${ }^{18,19}$.

Figure $5 \mathrm{~b}$ shows the relation between crystallized fraction and the time. From this curves it is possible to determine that the half crystallization time of PP was reduced with the incorporation of nanoparticles and that there is no difference between the different compositions. Saujanya ${ }^{16}$ showed that the crystallization kinetics is strongly dependent on particle size and Fornes ${ }^{17}$ showed that the crystallization kinetics of nylon 6/MMT nanocomposites depends on the MMT content. In our results the values obtained for $t_{1 / 2}$, crystallization temperature and level of crystallization show a tendency of become constant with the increase of calcium carbonate content, which can be a result of the agglomeration of nanoparticles. The results obtained in isothermal crystallization analyses together with the results obtained for crystallization temperature, level of crystallinity and reduced spherulitic size confirm the nucleation effect of calcium
Table 2. Data obtained from the isothermal analyses using Avrami equation.

\begin{tabular}{cccc}
\hline $\begin{array}{c}\text { Calcium carbonate } \\
\text { content (wt. \%) }\end{array}$ & $\begin{array}{c}\text { Avrami } \\
\text { índex (n) }\end{array}$ & $\begin{array}{c}\text { Kinetics } \\
\text { constant }(\mathrm{k})\end{array}$ & $\begin{array}{c}\text { Half crystallization } \\
\text { time }\left(\mathrm{t}_{1 / 2}\right)\end{array}$ \\
\hline PP (0) & 2,72 & $8,52 \mathrm{E}-05$ & 27 \\
$3 \%$ & 2,39 & $3,42 \mathrm{E}-04$ & 25 \\
$5 \%$ & 2,43 & $2,95 \mathrm{E}-04$ & 25 \\
$7 \%$ & 2,27 & $5,64 \mathrm{E}-04$ & 24 \\
$10 \%$ & 2,35 & $4,44 \mathrm{E}-04$ & 23 \\
\hline
\end{tabular}

carbonate nanoparticles in PP matrix, and give some evidences that this influence can be dependent on calcium carbonate content and dispersion.

\section{Conclusions}

In this work polypropylene/calcium carbonate nanocomposites were prepared with different filler contents. The effect of calcium carbonate nanoparticles in the crystallization process of polypropylene was studied with WAXD, DSC and polarized optical microscopy. WAXD results combined with DSC analyses showed the presence of PP $\beta$ phase in some nanocomposites indicating that nanoparticles affect the phase formation in polypropylene crystallization. Besides the formation of $\beta$ phase DSC results showed that the crystallinity degree and the crystallization temperature of PP increased with the addition of calcium carbonate nanoparticles. Polarized optical microscopy provided the spherulitic morphology of neat polypropylene and the nanocomposites showing the reduction of spherulites size with the incorporation of nanoparticles. From isothermal crystallization results it was concluded that nanoparticles accelerate the crystallization process of polypropylene, which is in accordance with other results that showed the nucleation effect of calcium carbonate nanoparticles in the crystallization process of polypropylene.

\section{References}

1. Rothon RN and Hancock M. General principles guiding selection and use of particulate materials. In: Rothon RN, editor. Particulate-Filled Polymer Composites. England: Longman Scientific \& Technical; 1995. p. $1-42$.

2. Tjong SC. Structural and mechanical properties of polymer nanocomposites. Materials Science and Engineering. 2006; 53: 73-197.

3. Thio YS, Argon AS, Cohen RE and Weinberg M. Toughening of isotatic polypropylene with $\mathrm{CaCO}_{3}$ particles. Polymer. 2002; 43(13): 3661-3674.

4. Zhang QX, Yu ZZ, Xie XL and Mai YW. Crystallization and impact energy of polypropylene/ $\mathrm{CaCO}_{3}$ nanocomposites with nonionic modifier. Polymer. 2004; 45(17): 5985-5994.

5. Chan $\mathrm{CH}, \mathrm{Wu} \mathrm{J}, \mathrm{Li} \mathrm{JX}$ and Cheung YK. Polypropylene/Calcium carbonate nanocomposites. Polymer. 2002; 43(10): 2981-2992.

6. Lin $\mathrm{Y}$, Chen $\mathrm{H}$, Chan $\mathrm{CM}$ and $\mathrm{Wu}$ J. High Impact Toughness Polypropylene/ $\mathrm{CaCO}_{3}$ Nanocomposites and the Toughening Mechanism. Macromolecules. 2008; 41(23): 9204-9213.

7. Eiras D and Pessan LA. Mechanical properties of polypropylene/calcium carbonate nanocomposites. Materials Research. 2009. Submitted.

8. Wan W, Yu D, Xie Y, Guo X, Zhou W and Cao J. Effects of Nanoparticle Treatment and Mechanical properties of Polypropylene/Calcium Carbonate Nanocomposites. Journal of Applied Polymer Science. 2006; 102(4): 3480-3488.

9. Moore EP. Polypropylene Handbook. Munich: Hanser-Munich; 1996. 
10. Yuan Y, Chen B and Zhang X. Study on the formation of $\beta$-crystal during the crystallization process of polypropylene reactor granule. Polymer. 2006; 47(15): 5480-5483.

11. Hou WM, Liu G, Zou JJ, Gao X, Li Y, Li L et al. The influence of crystal structures of nucleating agents on the crystallization behaviors of isotactic polypropylene. Colloid and Polymer Science. 2006; 285(1): 11-17.

12. Su Z, Dong M, Guo Z and Yu J. Study of Polystyrene and AcrylonitrileStyrene Copolymer as Special-Nucleating Agents to Induce the Crystallization of Isotatic Polypropylene. Macromolecules. 2007; 40(12): 4217-4224.

13. Chen HB, Karger Kocsis J, Wu JS and Varga J. Fracture toughness of $\alpha$ and $\beta$ phase polypropylene homopolymers and ramdom and block copolymers. Polymer. 2002; 43(24): 6505-6514.

14. Li JX, Cheung WL and Chan CM. On deformation mechanisms of $\beta$ polypropylene 2: Changes of lamellar structure caused by tensile load. Polymer. 1999; 40(8): 2089-2102.
15. Li JX, Cheung WL and Chan CM. On deformation mechanisms of $\beta$ polypropylene 3: Lamella structures after necking and cold drawing. Polymer. 1999; 40(13): 3641-3656.

16. Saujanya C and Radhakrishnan S. Structure development and crystallization behavior of PP/nanoparticulate composite. Polymer. 2001; 42(16): 6723-6731.

17. Fornes TD and Paul DR. Crystallization behavior of Nylon 9 nanocomposites. Polymer. 2003; 44(14): 3945-3961.

18. Silvestre C, Cimmino S, D’Alma E, Di Lorenzo ML and Di Pace E. Crystallization of isotatic polypropylene/natural terpene resins blends. Polymer. 1999; 40(18): 5119-5128.

19. Avella M, Cosco S, Di Lorenzo ML, Di Pace E, Errico ME and Gentile G. Nucleation activity of nanosized $\mathrm{CaCO} 3$ on crystallization of isotactic polypropylene, in dependence on crystal modification, particle shape, and coating. European Polymer Journal. 2006; 42(7): 1548-1557. 